\section{The related factors of phlebitis among low birth weight infants in perinatology ward}

\author{
Risna Yuningsih 1,2, Yeni Rustina1, \\ Defi Efendi1,3 \\ 1 Faculty of Nusing, Universitas \\ Indonesia; ${ }^{2} \mathrm{dr}$. Dradjat Prawiranegara \\ General Hospital Serang-Banten; \\ ${ }^{3}$ Neonatal Intensive Care Unit, \\ Universitas Indonesia Hospital, \\ Indonesia
}

\begin{abstract}
Peripheral intravenous line placement might lead to some risks and complications in low birth weight (LBW) infants including phlebitis, which shows varying percentages. This study aimed to analyze the causative factors of phlebitis among LBW infants in a perinatology ward. A total of 106 LBW infants who selected using a consecutive sampling technique were analyzed with cross-sectional method. Data were collected when LBW infants started receiving infusions until the infusion was stopped under certain conditions, using the Infusion Nurses Society (INS) phlebitis scale and the Neonatal Infant Pain Scale (NIPS) as the instrument. The variables related to phlebitis under bivariate analysis included the clinical experience of intravenous insertion, infusion pumps, site of insertion, neonatal birth weight, and the administration of total parenteral nutrition. The most significant risk factor of phlebitis was the nurses' clinical experience of intravenous insertion ( $<2$ years). Therefore, the results of this study can be considered to improve the quality of nursing care in perinatology ward.
\end{abstract}

\section{Introduction}

Peripheral intravenous line placement is a common procedure performed on neonates that could pose some risks and serious complications because the fragile skin might be susceptible to infectious organisms. One of these risks is the condition known as phlebitis.1,2 Peripheral intravenous line placement in premature infants has been proven to be an appropriate procedure during postnatal care. ${ }^{3}$ Nurses are required to have sufficient knowledge and understanding related to the type of access devices, the appropriateness of the selected devices for the administered therapy, the maintenance of the devices, and the potential complica- tion related to the devices and infusion fluids. ${ }^{2}$ Prolonged insertion of peripheral intravenous in neonates could be expensive, time-consuming, and significantly related to neonatal morbidity and increased incidences of phlebitis. ${ }^{4,5}$

The complications caused by intravenous infusion are more common compared to those of central infusion-with varied numbers of infiltration/extravasation $(2.9 \%-69.89 \%)$, phlebitis $(16.7 \%$ $25.4 \%$ ), and obstruction (12.27\%) incidences. ${ }^{6-10}$ The causative factors of phlebitis are the effects of total parenteral nutrition (TPN), antibiotics, infection, weight, blood transfusion, and the devices used. $7,8,11-13$ Nurses play an important role in performing intravenous insertion in neonates to prevent phlebitis. There is a significant correlation between nurses' knowledge of intravenous therapy and the incidences of phlebitis, and there is also a significant correlation between nurses' knowledge of intravenous therapy and patient comfort. 14 Therefore, paying attention to the risk factors for phlebitis is crucial to prevent phlebitis incidence in LBW infants.

Data from Hospital X in 2017 showed that the number of births was 3720 and $81.7 \%$ of them were high risks infants, for example LBW, premature and asphyxia, needing postnatal treatment in the hospital. Such numbers were in line with the numbers of intravenous therapy during hospitalization. Therefore, the researcher was interested in discovering the related factors of phlebitis in LBW infants.

\section{Materials and Methods}

This study employed a cross-sectional analytical design. The total sample size was 106 LBW aged less than 37 weeks. They were hospitalized in Hospital X and received peripheral infusions. The samples were selected using a consecutive sampling technique from March 2019 to May 2019 in the perinatology ward. The LBW infants were included under the criteria: i) weight $<2500$ grams; ii) gestational age $<37$ weeks; and iii) received a peripheral infusion. Infants with decreased consciousness were excluded from the study. The dependent variable was the incidence of phlebitis and the independent variables were weight, gestational age, medications, infusion fluids, the use of infusion pumps, the use of sterile infusion set in one pouch, the amount of clinical experience of the nurses in charge, the administration of TPN, and the infusion site selection.

Two instruments were used in this
Correspondence: Yeni Rustina, Pediatric Nursing Department, Faculty of Nursing, Universitas Indonesia, Jalan Prof. Dr. Bahder Djohan, Kampus UI Depok, West Java, 16424 Indonesia.

Tel.: +6221.78849120 - Fax: +6221.7864124.

E-mail: y_rustina@ui.ac.id

Key words: Peripheral intravenous; low birth weight infants; phlebitis.

Acknowledgments: The writer would like to express his gratitude to all the infants who participated in this study and their mothers.

Funding: This study was supported by Hibah PITTA B 2019, funded by DRPM Universitas Indonesia (No. NKB-0505/UN2.R3.1/HKP.05. 00/2019).

Contributions: RY substantial contributions to the conception of the work; acquisition, analysis, or interpretation of data for the work. YR and DE supervised the findings of this work; final approval of the version to be published. All authors discussed the results and contributed to the final manuscript.

Ethical approval: The practice received ethical approval from the Research Ethics Committee of the Faculty of Nursing, Universitas Indonesia (No.26/UN2.F12.D/HKP.02.04/2019).

Conflict of interest: There is no conflict of interest in this study.

This work is licensed under a Creative Commons Attribution NonCommercial 4.0 License (CC BY-NC 4.0).

C) Copyright: the Author(s), 2020

Licensee PAGEPress, Italy

Pediatric Reports 2020; 12(s1):8691

doi:10.4081/pr.2020.8691

study: the Infusion Nurses Society (INS) phlebitis scale and the Neonatal Infant Pain Scale. Other tools used in the study include the respondent characteristic forms, an observation checklist of phlebitis incidences, and the data of suspected factors. A hundred and six respondents were observed once after the infusions were removed to find out whether phlebitis occurs or not. The observations were conducted, and the forms were filled based on the data from medical records or the infant's daily observation sheets to determine the onset of phlebitis. The respondents who did not have any complications during intravenous insertion until the end of peripheral administration were not considered as having phlebitis. The data were analyzed using univariate, bivariate, and multivariate statistical analyses. Chi-square and Mann- 
Whitney U tests were used for the bivariate test (based on data characteristics), while logistic regression was used for the multivariate test.

\section{Results}

The results based on the respondent characteristics and the correlation between independent variables and phlebitis incidences can be seen in Table 1. Bivariate analysis showed that the independent variables indicating a significant correlation with phlebitis were the clinical experience of intravenous insertion ( $<2$ years), did not use infusion pumps, site of insertion, neona- tal birth weight, and the administration of total parenteral nutrition. The variables that did not indicate a significant correlation with phlebitis were gestational age, the type of infusion fluids, the type of medication, the use of infusion pumps, and the use of sterile set in one pouch during insertion. The percentage of phlebitis incidence observed in this study was $27 \%$.

The multivariate analysis was performed by entering the variable of $\mathrm{P}>0.25$ in the model. The results are presented in Table 2 .

The factors related to phlebitis in LBW infants were the nurses' clinical experience of intravenous insertion $(<2$ years), the administration of TPN for $<72$ hours and between 72 hours and 120 hours, the insertion site on the distal lower extremity, birth weight of 1000-1500 grams, and the use of infusion pumps. Meanwhile, the most dominant factor related to the incidences of phlebitis was the level of nurses' clinical experience.

\section{Discussion}

\section{Phlebitis incidences}

The result showed that $27 \%$ of the respondents suffered from phlebitis. Infusion Nurses Society suggests that the

Table 1. Distribution of respondents based on variables correlation with phlebitis incidences $(\mathrm{n}=106)$.

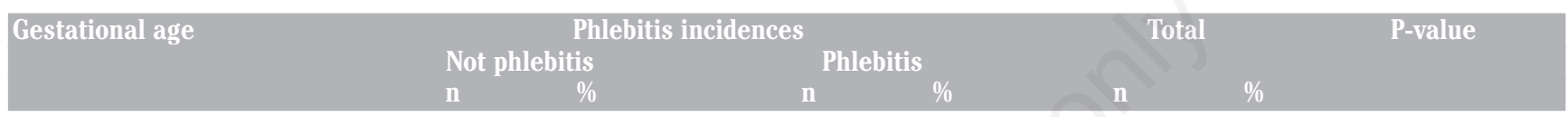

\section{Gestational age (1)}

$<28$ weeks

28-31 weeks

$32-36$ weeks

$>37$ weeks

$\begin{array}{ll}3 & 42.9 \\ 23 & 60.5 \\ 47 & 77.0 \\ 19 & 95.0\end{array}$

$\begin{array}{cc}4 & 57.1 \\ 15 & 39.5 \\ 14 & 23.0 \\ 1 & 5.0\end{array}$

$\begin{array}{cc}7 & 100 \\ 38 & 100 \\ 61 & 100 \\ 20 & 100\end{array}$

$\begin{array}{lccccccc}\text { Birth weight (2) } & 1 & 25 & 3 & 75 & 4 & 100 & 100 \\ 1500-2499 \text { grams } & 15 & 53.6 & 13 & 46.4 & 28 & 10000 \\ 1000-1500 \text { grams } & 57 & 77 & 17 & 23 & 74 & 100 \\ <1000 \text { grams } & & & & & \end{array}$

\begin{tabular}{|c|c|c|c|c|c|c|c|}
\hline \multicolumn{8}{|l|}{ Type of medication (3) } \\
\hline No drug & 0 & 0 & 2 & 100 & 2 & 100 & 0.004 \\
\hline Line I & 57 & 65.5 & 30 & 34.5 & 87 & 100 & \\
\hline Line II & 11 & 100 & 0 & 0 & 11 & 100 & \\
\hline Line III & 55 & 83.3 & 1 & 16.7 & 6 & 100 & \\
\hline \multicolumn{8}{|c|}{ Type of infusion fluids (4) } \\
\hline Without infusion fluids & 3 & 100 & 0 & 0 & 3 & 100 & 0.272 \\
\hline Hypotonic & 5 & 41.7 & 7 & 58.3 & 12 & 100 & \\
\hline Isotonic & 1 & 100 & 0 & 0 & 1 & 100 & \\
\hline Hypertonic & 64 & 71.1 & 26 & 28.9 & 90 & 100 & \\
\hline \multicolumn{8}{|c|}{ The administration of TPN (5) } \\
\hline Without TPNT & 39 & 88.6 & 5 & 11.4 & 44 & 100 & 0.001 \\
\hline PN 0-72 hours & 29 & 58 & 21 & 425 & 50 & 100 & \\
\hline TPN 72-120 hours & 4 & 44.4 & 5 & 5.6 & 9 & 100 & \\
\hline TPN $>120$ hours & 1 & 33.3 & 2 & 66.7 & 3 & 100 & \\
\hline \multicolumn{8}{|c|}{ The use of infusion pumps (6) } \\
\hline Using infusion pumps & 44 & 62.9 & 26 & 37.1 & 70 & 100 & 0.078 \\
\hline Not using infusion pumps & 29 & 80.6 & 7 & 19.4 & 36 & 100 & \\
\hline \multicolumn{8}{|c|}{ The use of sterile set in one pouch during insertion (7) } \\
\hline With a specific set & 14 & 93.3 & 1 & 6.7 & 159 & 100 & 0.034 \\
\hline Without a specific set & 59 & 64.8 & 32 & 35.2 & 1 & 100 & \\
\hline \multicolumn{8}{|l|}{ Insertion site (8) } \\
\hline Distal upper extremity & 30 & 75 & 10 & 25 & 40 & 100 & 0.125 \\
\hline Proximal upper extremity & 35 & 70 & 15 & 30 & 50 & 100 & \\
\hline Distal lower extremity & 7 & 46.7 & 8 & 53.3 & 15 & 100 & \\
\hline Proximal lower extremity & 1 & 100 & 0 & 0 & 1 & 100 & \\
\hline \multicolumn{8}{|c|}{ Clinical experience of intravenous insertion (9) } \\
\hline$>10$ years & 13 & 86.7 & 2 & 13.3 & 15 & 100 & 0.044 \\
\hline $6-10$ years & 36 & 69.2 & 16 & 30.8 & 52 & 100 & \\
\hline $3-5$ years & 23 & 69.7 & 10 & 30.3 & 33 & 100 & \\
\hline$<2$ years & 1 & 16.7 & 5 & 83.3 & 6 & 100 & \\
\hline
\end{tabular}

$(1,2,3,4,5,8$, and 9) Mann-Whitney U Test; ( 6 and 7) Chi Square Test; TPN, total parental nutrition. 
rate of phlebitis should be equal to or less than 5\%. ${ }^{14}$ Among the complications resulting from infusion insertion, $17.84 \%-77.5 \%$ were phlebitis. 7,15 Similar studies on pediatrics showed that phlebitis incidences ranged from $9 \%-71.25 \% .16,17$ The difference between these phlebitis incidences needs further analysis, especially those related to the phlebitis scale used. Until recently, there was no adequate and specific phlebitis scale for neonates. Identification of 71 phlebitis scales, three of which had been analyzed psychometrically, yet none of them has been strictly examined, and these might explain the significant difference among phlebitis scales and could be the cause of the difference in the reported phlebitis incidences. ${ }^{18}$ The hospital, where this study was conducted, might need to further explain the incidence discovery system and reporting. This study provides new insight related to the phlebitis incidences not only in neonates in general but also in more specific areas such as the LBW and preterm infants.

\section{The correlation between the level of clinical experience in intravenous insertion and phlebitis incidences}

The level of clinical experience of the nurses $(<2$ years) was significantly associated with the phlebitis incidences in LBW. The clinical conclusion is that the probability of phlebitis in LBW treated by $<2$ year-experience nurses was four times greater than those who were treated by $>10$ year-experience nurses. In a study done among nurses, intravenous insertion training was found to increase their knowledge and skill (31\% and $24 \%$, respectively). ${ }^{19}$ In another study, the clinical experience of infusion insertion significantly affected the duration of peripheral intravenous cannulation therapy. ${ }^{20}$ Studies have also demonstrated that there is a significant correlation between nurses' knowledge about infusion therapy and phlebitis incidences. ${ }^{14}$ In contrast, a study on neonates in New Zealand stated that the discipline of the inserter might not be the factor causing the peripheral intravenous complication. ${ }^{21}$ It is necessary to consider the clinical experience of the nurses in resolving the peripheral infusion cases in LBW.

\section{The correlation between neonatal birth weight and phlebitis incidences}

This research shows that the probability of suffering from phlebitis among LBW weighing 1000-1500 grams were five times greater than among LBW weighing 15002499 grams. Studies have shown that neonatal birth weight is associated with the infiltration/complication of extravasation and increases the risk of complication due to the small, fragile and less visible vein, and also the higher percentage of the adipose tissue. ${ }^{22}$ Findings from a case study of 590 grams neonates who suffered from phlebitis and exhibited malformation also support this claim. ${ }^{23}$ A study conducted in 2006 did not find any significant causes of extravasation associated with neonatal age and weight. ${ }^{24}$

\section{The correlation between total par- enteral nutrition administration and phlebitis incidences}

The duration for TPN was correlated with the incidences of phlebitis. The longer the insertion, the higher the risk of phlebitis. TPN is the nutrient administered through the blood vessel and contained an amino acid, glucose (10-20\%), and lipid emulsions $(10-20 \%)$. The fluid should preferably be administered through the central blood vessels. However, it could also be administered through the peripheral veins, if the osmolality allows ranged from 800 to 1200 mOsm/L. ${ }^{11,25}$ The small and fragile neonatal veins make cannulation difficult, exhibit low tolerance to $\mathrm{pH}$ change and osmolarity, which could trigger thrombophlebitis in neonates who received hypertonic solution. ${ }^{4}$ Phlebitis has been reported as the most common complication during TPN through peripheral access in neonates $(3 \%$ $31 \%$ ). 25 This emphasizes the fact that high

Table 2. Multivariate analysis with backward method between selected independent variables and phlebitis incidences $(n=106)$.

\begin{tabular}{lccc} 
Variable & B & Sig. & Exp (B) \\
Clinical experience (<2 years) & 4.350 & 0.015 & 77.516 \\
TPN 72-120 hours & 3.260 & 0.006 & 26.054 \\
\hline TPN 0-72 hours & 2.743 & 0.002 & 15.538 \\
Distal Lower Extremity & 2.884 & 0.014 & 17.887 \\
\hline Weight 1000-1500 grams & 1.660 & 0.037 & 5.257 \\
Not using infusion pumps & -2.051 & 0.032 & 0.112 \\
\hline Constanta & -3.920 & &
\end{tabular}

TPN, total parenteral nutrition. osmolarity fluids could increase the risk of phlebitis incidences because of the size and fragility of the veins of LBW. The process of TPN liquid compounding was performed in the nursing room before it was administered to the respondents. Some studies have revealed that the TPN compounding should be conducted all in one by central pharmacy under a closed system. ${ }^{26}$ The findings of this study suggest that the administration of TPN should be given through central venous, and the nutrient fluid compounding should be conducted by pharmacy staff in a closed system.

\section{The correlation between infusion pumps and phlebitis incidences}

The findings of this study showed an inverse relationship between the use of infusion pumps and phlebitis incidences, i.e., if the infusion pump is used, the risk of phlebitis increases. Infusion pumps could help to control the consistency of fluid volume entering the patient's body during the administration of peripheral intravenous. In general, the infusion pump alarm will give a signal when the fluid is altered due to occlusion, but it cannot detect the early infiltration. The pressure caused by the infiltration cannot trigger the alarm because it is lower than the pressure caused by occlusion. ${ }^{27}$ When the gravity method is applied to administer the infusion or medication in pediatrics, the duration of peripheral infusion becomes longer $(72.56 \pm 35.85$ hours $)$ compared to when electronic pump or puncture is applied $(60.03 \pm 33.88$ hours $) .^{28}$ Research has demonstrated that $72 \%$ to $99 \%$ of clinical alarms are false. The high number of false alarms has led to alarm fatigue, which can result in the desensitization of alarms and missed alarms. ${ }^{29}$ The findings of this study suggest that the incidences of phlebitis related to the use of infusion pumps is affected by other factors.

\section{The correlation of insertion site and phlebitis incidences}

The selection of peripheral intravenous insertion site in the distal lower extremity was significantly associated with the incidences of phlebitis in LBW infants $(\mathrm{P}=0.019)$. A study found that the insertion site in the arm area affected the length of insertion without complication.20,30 Found a different result reported that the insertion site of peripheral intravenous in neonates did not correlate with the infusion complication. Further research related to the site selection in neonates is required because the infusion insertion in LBW infants is quite risky, and the blood vessels of the babies are small, fragile, and can be easily damaged by pressure. 


\section{Conclusions}

The factors that have been proven to be significantly correlated with the incidences of phlebitis in LBW were the clinical experience of intravenous insertion $(<2$ years), did not use infusion pumps, site of insertion, neonatal birth weight, and the administration of total parenteral nutrition. Gestational age, the type of infusion fluids, the type of medication, the use of infusion pumps, and the use of sterile set in one pouch during insertion did not correlate with the incidences of phlebitis in LBW in perinatology ward. Multivariate analysis revealed that the most significant factor is the level of clinical experience of the nurses in charge.

\section{References}

1. Beall V, Hall B, Mulholland JT, Gephart SM. Neonatal extravasation: An overview and algorithm for evidencebased treatment. Newborn Infant Nurs Rev 2013;13:189-95.

2. Phillips LD, Gorski L. Manual of I.V. therapeutics evidence-based practice for infusion therapy. 6th Ed. Philadelphia: F. A. Davis Company; 2014.

3. Baik-Schneditz N, Pichler G, Schwaberger B, et al. Peripheral intravenous access in preterm neonates during postnatal stabilization: feasibility and safety. Front Pediatr 2017;5:5-7.

4. Tandale SR, Dave N, Garasia M, et al. A study of morbidity and cost of peripheral venous cannulation in neonates admitted to paediatric surgical intensive care unit. J Clin Diagn Res 2017;11: UC08-UC10.

5. Uslusoy E, Mete S. Predisposing factors to phlebitis in patients with peripheral intravenous catheters: A descriptive study. J Am Acad Nurse Pract 2008;20: 172-80.

6. Barría RM, Lorca P, Muñoz S. Randomized controlled trial of vascular access in newborns in the neonatal intensive care unit. J Obstet Gynecol Neonatal Nurs 2007;36:450-6.

7. Danski MTR, Mingorance P, Johann DA, et al. Incidence of local complications and risk factors associated with peripheral intravenous catheter in neonates. Rev Esc Enferm USP 2016;50:22-8.

8. Gomes ACR, Silva CAG da, Gamarra
CJ, et al. Assessment of phlebitis, infiltration, and extravasation events in neonates submitted to intravenous therapy. Esc Anna Nery 2011;15:472-9. 9. Özalp Gerçeker G, Kahraman A, Yardimci $F$, et al. Infiltration and extravasation in pediatric patients: A prevalence study in a children's hospital. J Vasc Access 2018;19:266-71.

10. Webster J, McGrail M, Marsh N, et al. Postinfusion phlebitis: incidence and risk factors. Nurs Res Pract 2015; 2015:1-3.

11. Embleton ND, Simmer K. Practice of parenteral nutrition in VLBW and ELBW infants. World Rev Nutr Diet 2014;110:177-89.

12. Milutinović D, Simin D, Zec D. Risk factor for phlebitis: A questionnaire study of nurses' perception. Rev LatinoAm Enfermagem 2015;23:677-84.

13. Salgueiro-Oliveira A, Parreira P, Veiga P. Incidence of phlebitis in patients with peripheral intravenous catheters: The influence of some risk factors. Aust J Adv Nurs 2012-2013;30:32-9.

14. Wayunah W, Nurachmah E, Mulyono S. Pengetahuan perawat tentang terapi infus memengaruhi kejadian plebitis dan kenyamanan pasien. Jurnal Keperawatan Indonesia 2013;16:128-37.

15. Lu Y, Hao C, He W, et al. Experimental research on preventing mechanical phlebitis arising from indwelling needles in intravenous therapy by external application of mirabilite. Exp Ther Med 2018;15:276-82.

16. de Lima Jacinto AK, Avelar AF, Wilson AM, Pedreira MD. Phlebitis associated with peripheral intravenous catheters in children: Study of predisposing factors. Esc Anna Nery - Rev Enferm 2014;18:220-6.

17. Nagpal P, Khera GK, Kumar Y. A study assess the clinical pattern of phlebitis among children admitted in selected hospital of Ambala, Haryana. Nurs Midwifery Res J 2015;11:68-77.

18. Ray-Barruel G, Polit DF, Murfield JE, Rickard CM. Infusion phlebitis assessment measures: A systematic review. J Eval Clin Pract 2014;20:191-202.

19. Keleekai NL, Schuster CA, Murray CL, et al. Improving nurses' peripheral intravenous catheter insertion knowledge, confidence, and skills using a simulation-based blended learning program: A randomized trial. Simul Healthc 2016;11:376-84.

20. Birhane E, Kidanu K, Kassa M, et al.
Lifespan and associated factors of peripheral intravenous cannula among infants admitted in public hospitals of Mekelle City, Tigray, Ethiopia, 2016. BMC Nurs 2017;16:1-8.

21. August D, Ullman AJ, Rickard CM, New K. Peripheral intravenous catheter practices in Australian and New Zealand neonatal units: A cross-sectional survey. J Neonatal Nurs 2019;25: 240-4.

22. Atay S, Sen S, Cukurlu D. Incidence of infiltration/extravasation in newborns using peripheral venous catheter and affecting factors. Rev Esc Enferm USP 2018;52:1-5.

23. Bolcato M, Russo M, Donadello D, et al. Disabling outcomes after peripheral vascular catheter insertion in a newborn patient: A case of medical liability? Am J Case Rep 2017;18:1126-9.

24. McCullen KL, Pieper B. A retrospective chart review of risk factors for extravasation among neonates receiving peripheral intravascular fluids. J Wound Ostomy Continence Nurs 2006;33:133-9.

25. Pertkiewicz M, Dudrick SJ. Basics in clinical nutrition: Parenteral nutrition, ways of delivering parenteral nutrition and peripheral parenteral nutrition (PPN). E Spen Eur E J Clin Nutr Metab 2009;4:125-7.

26. Zingg W, Tomaske M, Martin M. Risk of parenteral nutrition in neonates - An overview. Nutrients 2012;4:1490-503.

27. Bala P, Ryan CA, Murphy BP. Hospital admissions for bronchiolitis in preterm infants in the absence of respiratory syncytial virus prophylaxis. Arch Dis Child Fetal Neonatal Ed 2005;90: 92-5.

28. Ben Abdelaziz R, Hafsi H, Hajji H, Boudabous $\mathrm{H}$, Ben CA, Mrabet A, Boussetta K, Barsaoui S, Sammoud A, Hamzaoui M, Azzouz H. Peripheral venous catheter complications in children: Predisposing factors in a multicenter prospective cohort study. BMC Pediatr 2017;17:1-11.

29. Sendelbach S, Funk M. Alarm fatigue: A patient safety concern. AACN Adv Crit Care 2013;24:378-86.

30. Legemaat M, Carr PJ, van Rens RM, van Dijk M, Poslawsky IE, van den Hoogen A. Peripheral intravenous cannulation: Complication rates in the neonatal population: A multicenter observational study. J Vasc Access 2016;17:360-5. 